\title{
NOTES ON GLUPHISIA AND OTHER NOTODONTIDAE.-II.
}

\author{
BY A. S. PACKARD, PROVIDENCE, R. I.
}

The structural differences between $G$. trilineata and $G$. wrightii, var. slossoniae, and which at first led me to think them generically distinct, are the following :

A $\$$. The head is remarkably small, much more so than in G.trilineata; and is loosely scaled in front. The antennae are pectinated, the branches a little longer than in $\$$ trilineata. The palpi are short, small, depressed, with loose scales; and they are not quite so large and long as in trilineata. The thorax differs from that of Gluphisia trilineata in having a median dorsal tuft. The legs are hairy, and much as in trilineata, the tarsi being ringed with gray and darker scales. The fore wings are narrow but with the costa unusually convex, much more so than in trilineata; the apex is somewhat rounded, but much as in trilineata; the outer edge is very faintly excavated below the apex. The hind wings are of the same shape as in trilineata. There are six branches of the subcostal vein: branch $I$ is longer than in trilineata and ends half way between end of costal vein and end of branch 2 of the subcostal; the costal area is wider towards apex than in trilineata. The $5^{\text {th }}$ and 6 th branches are nearly as in trilineata. The lower discal vein is not so much bent as in the last named species. The three median veins are nearly as in trilineata, but the $2 \mathrm{~d}$ median space is wider than in that genus. The submedian vein is represented by a simple fold. In the hind wings the two branches of the subcostal are much longer than in trilineata, the space between them being long and narrow, in trilineata short and broad triangular. The discal veins are, taken together, slightly curved, where in trilineata they make a decided angle at the origin of the independent vein; and there is a common origin of the lower discal, and of the two median veinlets. The second median interspace is much wider than in the species of the other section of the genus. The submedian vein is represented by a simple fold.

G WRIGHTII VAR. SLOSSONIAE.-Body and wings pale ash-gray; the prothoracic segment colored as the head, but the rest of the thorax is dark brown, the median thoracic tuft also dark brown. Fore wings black-brown on basal one-fifth; this portion sending out five sharp tooth-like projections along the subcostal, submedian and internal veins. A broad distinct median oblique band, with irregular lobulate edges, and widening on the costa; it encloses a very distinct discal triangular white spot, the apex pointing outwards. A submarginal broken row of dark spots arranged much as in Gluphisia trilineata.

Hind wings with no markings, but at the inner angle is a faint short curved dark band, edged externally with white, but not reaching beyond the middle of the submedian space. Fringe concolorous with the wing, but checkered with small black spots.

Wings beneath much as in Gluphisia trilineata; the black band is faint, its outer edge indicated on the costa by a dark spot. Expanse of wings, $38 \mathrm{~mm}$; length of body, $\mathrm{r}_{5}$ $\mathrm{mm}$.

Nadata Behrensil H. Edw. Types, 2 o I 9 . Siskiyou Co. and Butte Co. Cal. This does not seem to differ from $N$. gibbosa. The $q$ has a paler body and wings, the fore wings are more pointed, and as in many Pacific coast moths, it is larger than the eastern form of gibbosa. On examining my type of $N$. doubledayi in the collection of the American entomological society I find that it is not even a variety of gibbosa. It only differs in having the under side 
of the palpi and of the fore legs dusky. Oedemasia perangulata H. Edw I $\delta$. Type, Colorado. A very distinct and good species.

Oedemasia salicis i $\delta$. Type, California. I also have a $\delta$ given me some years since by Mr. Edwards. I cannot after repeated examination really perceive any differences between this and the eastern concinna ; it only differs in size, being a little larger, and with slightly more pointed fore wings, as one would expect to find it, in accordance with the facts pointed out in my Monograph of Geometrid Moths ( $\mathrm{p}$. 587 ) where a list of twenty-five species of Geometrids which grow larger on the Pacific than the Atlantic coast is given.

Oedemasia eximia Grote. I have been unable to find any valid distinctions between this and concinna (also salicis), except that the insect is larger, and the fore wings more produced towards the apex. The females of the normal concinna differ notably from the males in having pale chocolate hind wings, while in the males they are white, with a dusky patch at the internal angle. The three above mentioned so-called "species" also agree in having a similar distinct round discal dot.

OE. BAdia Pack. is a distinct species, and differs from Oe. concinna in the long linear discal spot, outside of which is a dark reddish brown shade. There are also distinct scalloped reddish brown lines at the base, and beyond the discal spot. The thorax is also darker red.

Oe. Perangulata H. Edw. Type from Colorado. This is a distinct, well marked species.
On re-examining the venation and other imaginal characters $I$ am at present unable to perceive any important generic differences between Oedemasia and Schizura, and probably the species of the former will have to be merged with those of Schizura.

Schizura edmandsil (Pack.). This is evidently a synonym of $S$. unicornis. The specimen ( $\delta$ ) marked edmandsii in Mr. Edward's collection appears to be only a small unicornis with narrower wings than usual. The only difference is in the dusky tawny costa of the fore wings, and the similarly tinted hind wings, due perhaps to imperfect preservation.

S. conspecta (H. Edw.). I $\delta$. Type, California. This is only a climatic variety of $S$. unicornis; the position of the markings is identical in the two forms, but conspecta is larger, the fore wings as much produced as in any of unicornis. The pale area on the outer third of the wing is clear and whitish, and the hind wings are clearer and whiter than in any eastern example of unicornis.

S. Telifer (Grote). This is only a variety of $S$. ipomeae, with two long distinct black streaks, one passing through the discal spot, and the other extending along the submedian vein.

Janassa coloradensis H. Edw. Type. 3 , Utah A climatic variety of $\mathcal{F}$. lignicolor. It is whiter, paler, freer from dark scales, probably due to living in a drier climate, flying over a paler soil, under a clearer sky. Yet an individual of $\mathcal{F}$. lignicolor from Georgia, in the same collection, comes very near it. 

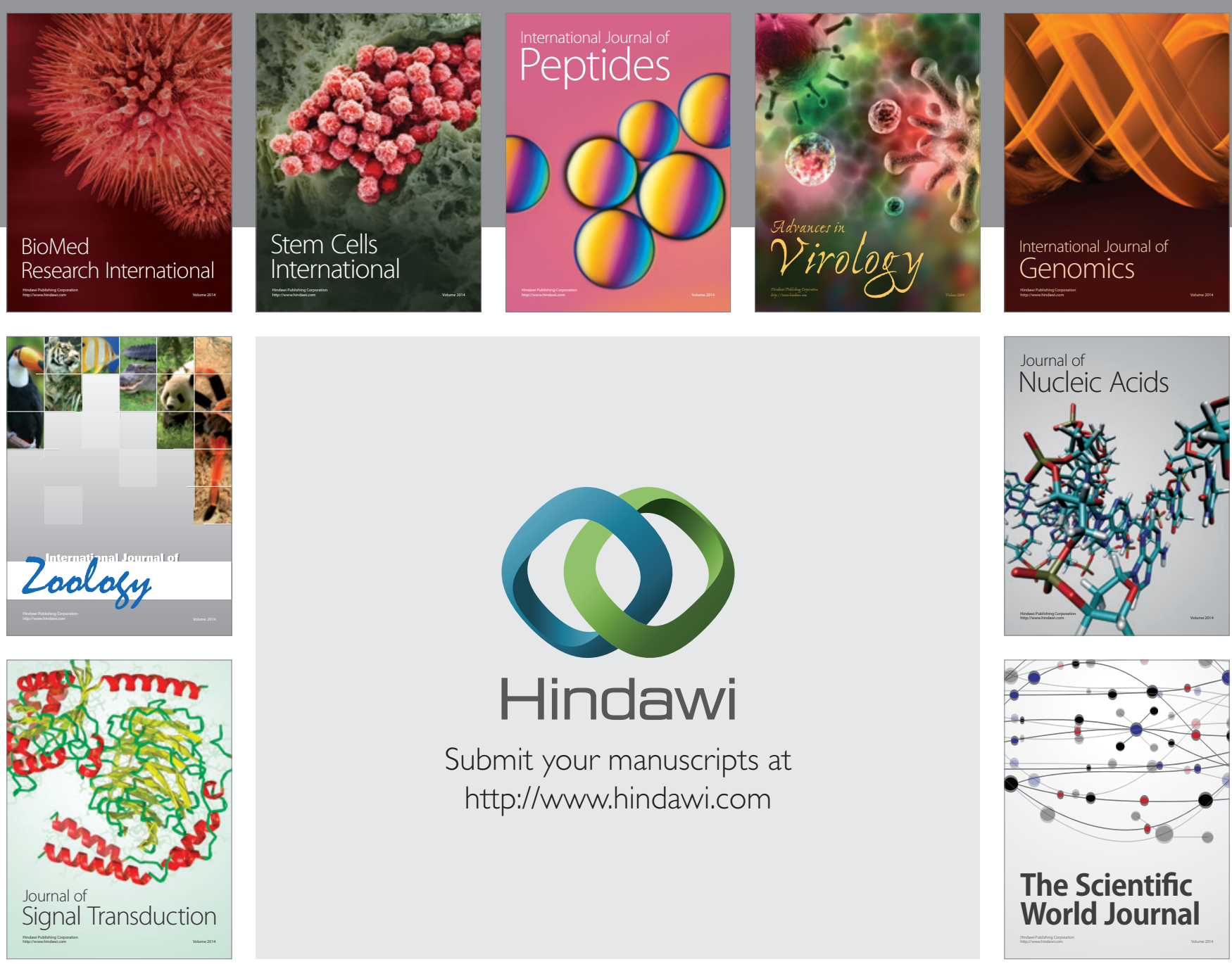

Submit your manuscripts at

http://www.hindawi.com
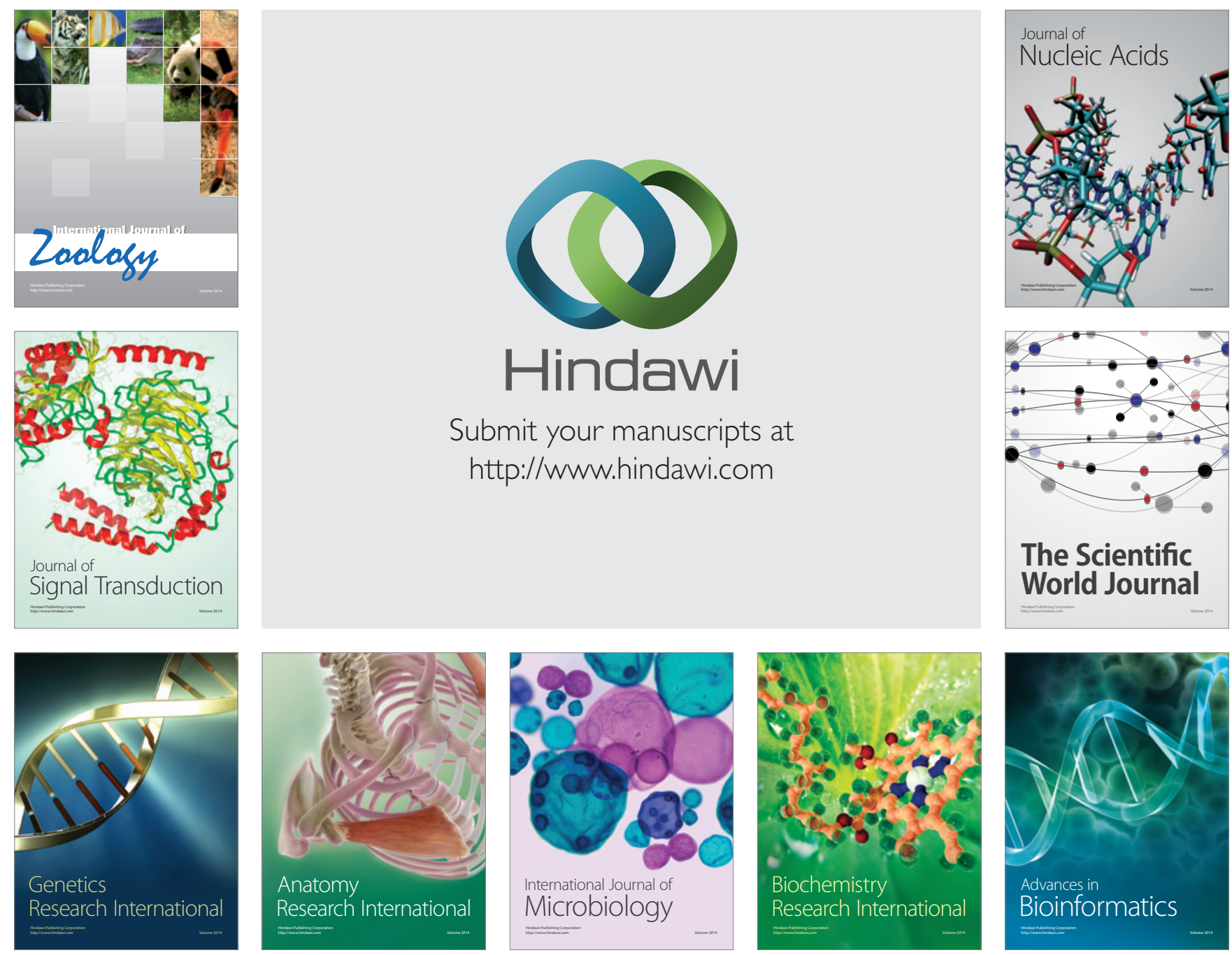

The Scientific World Journal
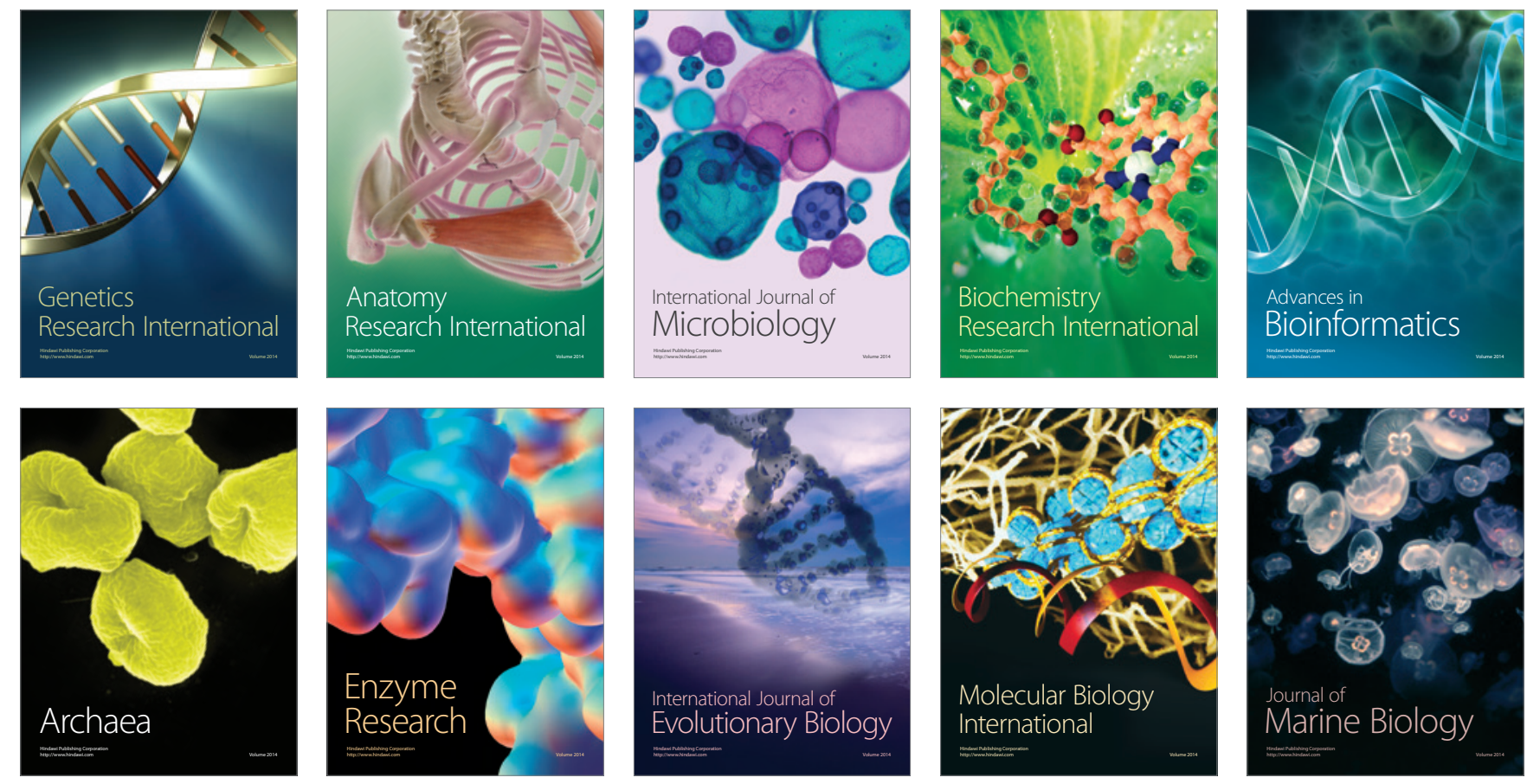